\title{
Cavernous weathering forms in SW Iceland: a case study on weathering of basalts in a cold temperate maritime climate
}

\begin{abstract}
The article is a case study of the development of cavernous weathering forms (alveoli and tafoni) on a sea cliff near Keflavik on the Reykjanes peninsula in southwestern Iceland. The majority of forms are found on vertical or inclined rock faces and cluster around the uppermost edge of the cliff. Single hollows gradually evolve due to back wearing of their sidewalls into complex caverns, until finally the whole outermost layer of basalt is removed. Particular attention is paid to mineralogical changes of basalts due to chemical and salt weathering. Chemical decomposition of feldspars, pyroxenes and olivines followed by precipitation of iron on and within the weathering rind, the presence of micro- and macro-pores such as gas bubbles and delivery of marine salts are proposed to be the key factors influencing cavern development.
\end{abstract}

Keywords

Tafoni $\bullet$ basalt weathering $\bullet$ Iceland $\bullet$ hydrogen

(C) University of Warsaw - Faculty of Geography and Regional Studies

\author{
Katarzyna Zwalińska ${ }^{1}$ \\ Maciej Dąbski ${ }^{2}$ \\ ${ }^{1}$ Institute of Physical Geography, \\ Faculty of Geography and Regional Studies, \\ University of Warsaw \\ e-mail: kasia.zwalinska@gmail.com \\ 2Institute of Physical Geography \\ Faculty of Geography and Regional Studies, \\ University of Warsaw \\ e-mail:mfdbski@uw.edu.pl \\ Received: 13 February 2012 \\ Accepted: 15 June 2012
}

\section{Introduction}

Selective weathering of rock leading to the development of peculiar phenomena such as cavernous weathering forms (alveoli, honeycomb and tafoni) in a variety of climates and rock types has been examined extensively (Benito \& Sancho 1990; Doe 2004; Hacker 2003; Hall \& André 2006; Hejl 2005; Jennings 1968; Martini 1978). Goudie (2004a, b, c) and Turkington (2004) provide useful summaries. In cold climates in particular, frost and salt weathering operate together which results in cavernous weathering and the formation of tafoni structures (Williams \& Robinson 1991; also summarized by French 1996). Cavernous weathering forms frequently develop under maritime climatic conditions, where they are influenced by the delivery of salt and water to rock faces by sea aerosol and snow (André \& Hall 2005; French 1996; French \& Guglielmin 2000; McKeever et al. 1990). An important factor governing tafoni initiation is the presence of discontinuities in rock structure, texture or lithologywhich favour differential weathering (Hacker 2003). At the micro-scale, discontinuities such as fractures within quartz crystals in rock exposed to saline-moderated freeze-thaw cycles probably promote cryogenic cavernous weathering in Antarctica (French \& Guglielmin 2000). Doe (2011) described the geometry of honeycomb weathering forms developed in sandstone and argued that they are formed by residual salts from pore moisture drawn to the rock surface, but this process is most likely restricted to warm climatic conditions with significant potential evaporation.

Cavernous weathering forms are usually associated with sandstones (Young \& Young 1992) and granite (Dragovich 1969). Basaltic tafoni and honeycomb forms are rarely reported but in the maritime climatic conditions of the Antrim coast of Northern Ireland, cavernous hollows developed on basalt cliffs, where their formation is attributed to the presence of salts and clay mineral expansion (McKeever et al. 1990). In this study, we examine tafoni and alveoli in basalt from a climatic regime similar to Northern Ireland in order to determine whether these same processes are responsible for their formation in Iceland and are thus more universal. To address this, we examine the locational, morphological and chemical characteristics of the basalt and the tafoni and weathering products along a stretch of basaltic cliff near Keflavik, Iceland. Our findings emphasize the role of chemical weathering and decomposition of feldspars, pyroxenes and olivines, followed by iron precipitation on and within the weathering rind, the presence of macro- and micro-pores and sea salt, as the main factors controlling cavernous weathering of basalt in this location. 
MISCELLANEA GEOGRAPHICA - REGIONAL STUDIES ON DEVELOPMENT

Vol. 16 • No. 1 • 2012 • pp. 11-16 • ISSN: 2084-6118 • DOI: 10.2478/v10288-012-0016-3

\section{Study site}

The study was performed on a sea cliff of Holmsberg, located north of Keflavik, a port on the northwestern coast of the Reykjanes peninsula in Iceland (Fig. 1). The majority of the inspected rock surfaces are oriented toward the northeast or southeast on a cliff that varies from 5-25 $\mathrm{m}$ in height. The Reykjanes peninsula lies within the youngest geological formation of Iceland, currently undergoing volcanic activity (Einarsson 1999). The studied sea cliff is built of Pleistocene tholeiite basalts of grey colour,and contains numerous spherical macro-pores and vesicles (diameter 1-3 mm) inherited from cooling lava. The rock consists of large, chaotically placed crystals of feldspars (anorthite), constituting over $50 \%$ by volume and a matrix dominated by pyroxene (augite) and accessory minerals such as biotite, magnetite, apatite, ilmenite and olivine. These observations position the analysed basalts in the 9th and 10th field of the QAPF diagram (Majerowicz \& Wierzchołowski 1990). Crystal sizes vary from $0.2 \mathrm{~mm}$ to $1 \mathrm{~mm}$.

The Peninsula experiences a cold temperate maritime climate that is strongly influenced by the Irminger Current, a branch of the North Atlantic Current, resulting in mean annual air temperatures of $4.3^{\circ} \mathrm{C}$ with only $10.7^{\circ} \mathrm{C}$ annual amplitude, and an annual precipitation of $1103 \mathrm{~mm}$. Due to low pressure systems passing frequently along the southern coast of Iceland, wind velocities are high; mean monthly values are usually within 4-7 $\mathrm{ms}^{-1}$ (Einarsson 1984, Szumska 1998).

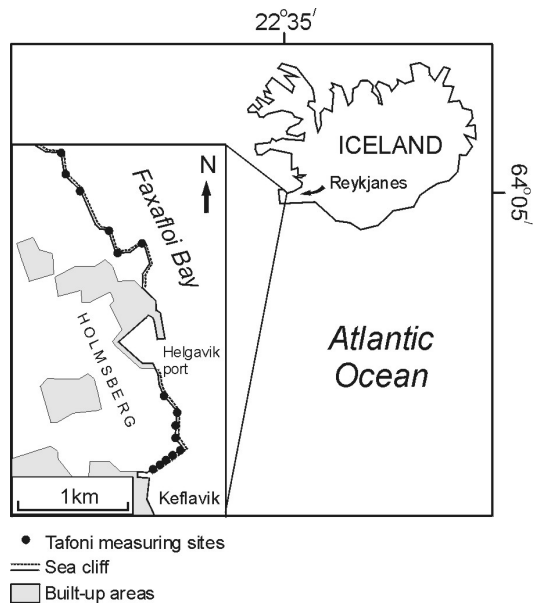

Fig 1. Location of the study area

\section{Methods}

Measurements of cavernous forms (Turkington 2004) were performed in the summer of 2010 at 15 sites located along the cliff (Fig. 1). The sites were chosen in a variety of places in order to cover as many diverse forms as possible. In each of the sites, hollows were measured within an area of $4 \mathrm{~m}^{2}$. The three dimensions of 1112 tafoni and alveoli were measured using $a, b$ and $c$ axes (Figs. 2 and 7). The forms were divided into simple and complex caverns, the latter developing when two or more small forms combine (Goudie 2004a). Samples of intact rock, weathering rinds and loose rock debris found within tafoni were taken for laboratory investigations.
Thin sections of intact rock and weathering rinds were photographed and analysed under an optical microscope, a scanning electron microscope (SEM) and X-ray diffraction in order to determine their mineralogical and chemical composition. Rock debris was measured in order to determine its granular composition and the shapes of rock fragments.
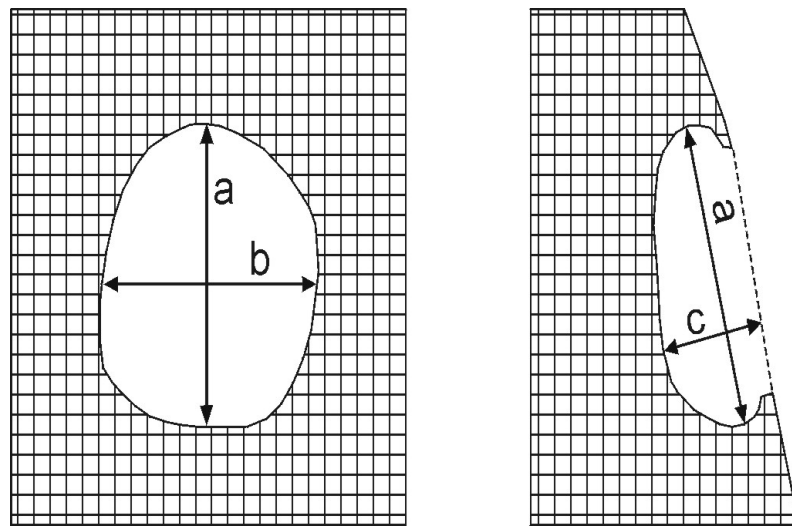

Fig 2. Measured dimensions of cavernous forms

\section{Results}

The tafoni usually cluster around the upper edge of a sea cliff (Fig. 3) and appear as single hollows or complex caverns in vertical, or nearly vertical, rock faces. Single caverns are separated from each other by walls, frequently hardened by salts and iron compounds that manifest as a darker rock surface colour, which oftens leads to a characteristic " $C$ " shape overhanging of the outer walls. In some places, honeycomb-like structures (or alveoli) occur on horizontal surfaces of loose basaltic blocks (Figs. 4 and 6) and could thus be called weathering pits (Goudie 2004b). On the other hand, Doe (2004) describes alveoli developed on almost horizontal surfaces, so the term 'horizontal honeycomb' seems appropriate.

Well-developed composite tafoni or honeycomb caverns are found near the edges of the cliff, where seawater aerosol can be intensively delivered, and within small bays in the cliff. The majority of caverns are found in places of structural discontinuities of basalt and where vegetation is absent.

Morphometrical analysis reveals that the depth of cavernous forms (c axis) remains relatively constant, while the diameter of he forms ( $a$ and $b$ axes) varies considerably (Fig. 7). Weathered rock debris can be found only in a few honeycombs or tafoni. Where present, the coarse sand fraction dominates the weathered material. All debris is angular and the larger fragments (gravel size $0.5-2 \mathrm{~cm}$ ) have lamellar shapes.

Chemical weathering is manifested by the occurrence of a weathering rind (average thickness $0.5 \mathrm{~mm}$ ) that is clearly visible both in the field and under an optical microscope. The colour of the weathered basaltic surface is light grey and yellowbrown or reddish. Petrographic analysis revealed that the intact inner parts of basalt include a large amount of silica $\left(\mathrm{SiO}_{2}\right)$ found within silica-rich feldspars and pyroxenes. On the other hand, the weathering rinds are characterized by relatively less silica and 


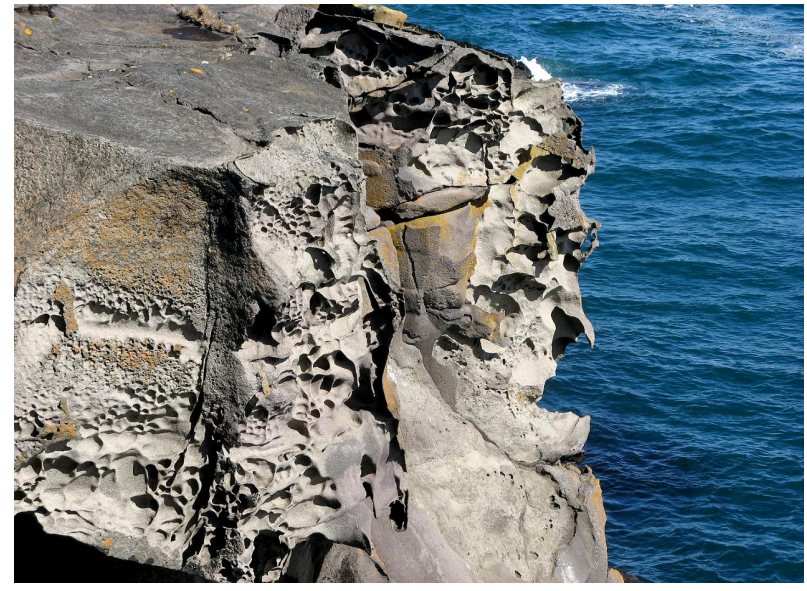

Fig 3. Tafoni and honeycombs developed at the edge of the basaltic sea cliff of Holmsberg (phot. K. Zwalińska)

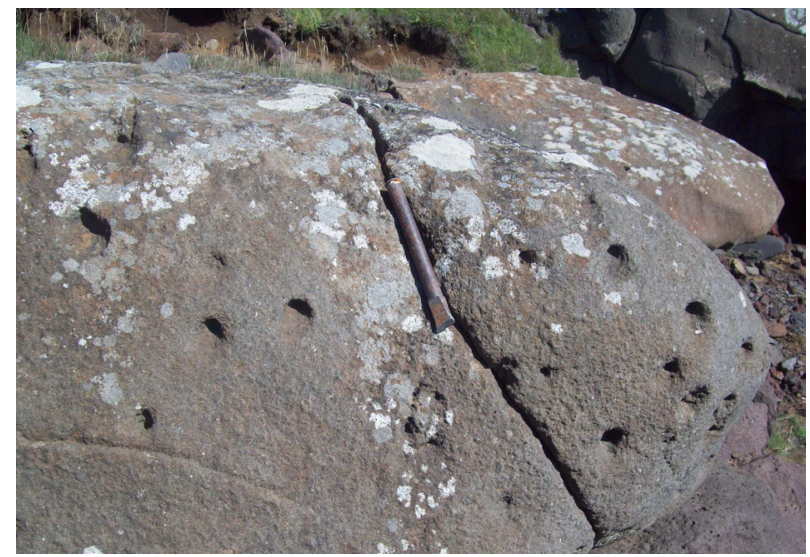

Fig 5. Single alveoli (phot. K. Zwalińska)

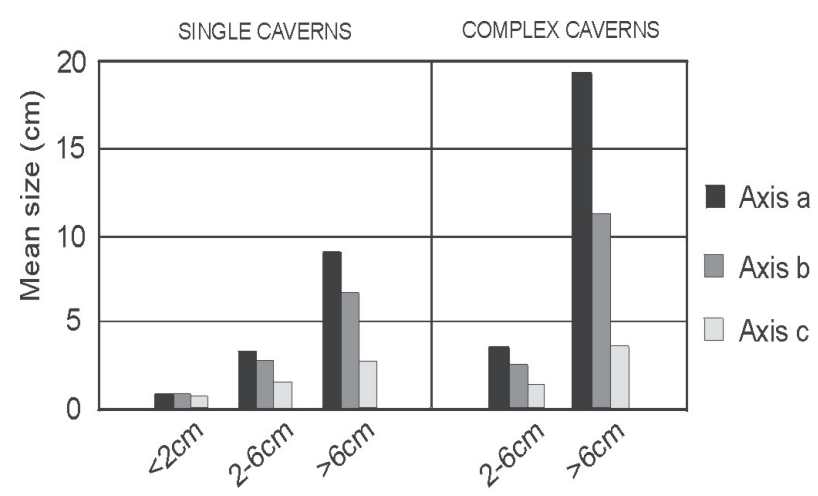

Size groups based on axis a

Fig 7. Averaged results of morphometric measurements

a lower olivine content. X-ray diffractometry and SEM analysis of rock samples showed that the surfaces of feldspars and pyroxenes within the weathering rind are enriched with chlorine, manganese and sodium. These elements were not found inside intact rock, beyond the weathering rind.

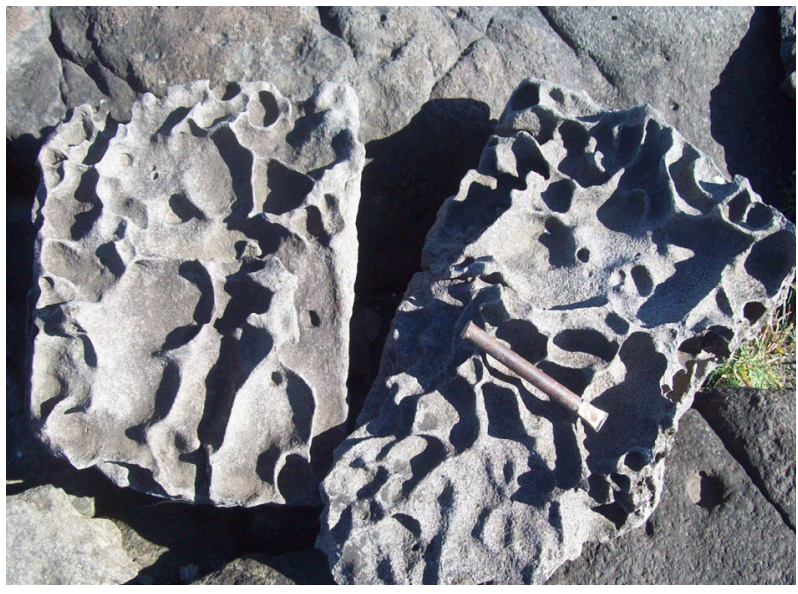

Fig 4. Honeycomb weathering in the basaltic surfaces (phot. K. Zwalińska)

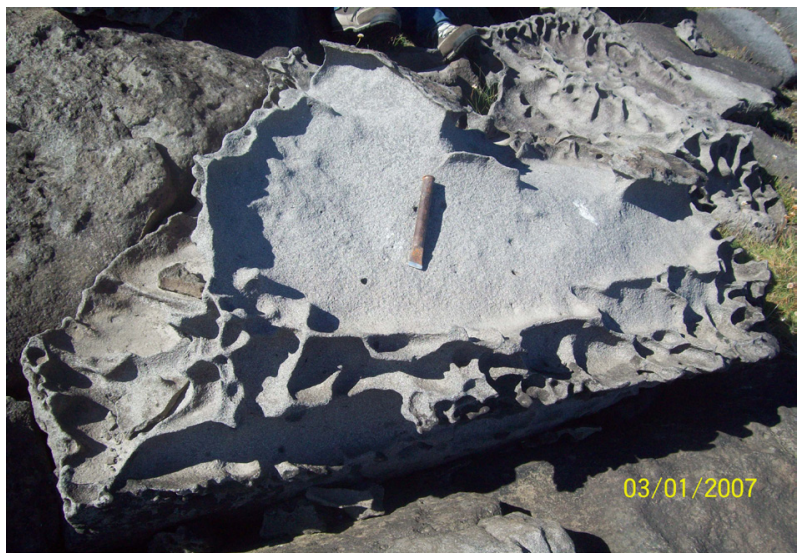

Fig 6. Large and complex horizontal cavern or weathering pit (phot. K. Zwalińska)

Intact parts of basalt have relatively small pore spaces, except for those formed by gas bubbles created during cooling of lava. The diameters of such macro-pores ranges from $1 \mathrm{~mm}$ to $3 \mathrm{~mm}$. In the weathering rind there are also numerous pores inherited from dissolved minerals in addition to the bubbles.

\section{Discussion}

Location controls and mode of origin

Observations of single and complex caverns suggest that advanced backwearing of a the side walls of a single cavern leads to the coalescence of a few adjacent hollows, thereby creating a complex, but relatively shallow, depression in the basaltic surfaces (Figs. 4 and 6). In places, honeycomb-like structures occur on the horizontal surfaces of basaltic blocks lying on the Holmsberg cliff-top, near the uppermost edge of the cliff. In such cases it appears that slightly different processes are able to operate on the horizontal rock surfaces as a result of stagnant water accumulating in depressions. However, the features closely resemble the honeycomb forms found on vertical faces and described by Doe (2004). A possible explanation of 'horizontal honeycombs' is that strong wind and the shallow depth of the depressions do 
not allow for standing water, making conditions of weathering on vertical and horizontal surfaces quite similar. The action of strong wind can be inferred from the fact that very little rock debris was found in depressions due to its removal by deflation.

The relatively constant depth of depressions (c axis) despite a vide variety of $a-$ and $b$ - axis $b$ lengths suggests that inward deterioration of rock (or downward deterioration in the case of 'horizontal honeycombs') is followed by lateral broadening when c-axis erosion slows down. Lamellar or platy shapes of gravelsize debris testify to exfoliation operating on the rock walls. When the outer rock surface hardens due to iron precipitation it becomes vulnerable to erosion under the hardened surface where more moisture can be retained, promoting side-wearing and depression widening (Martini 1978, Doe 2011). Eventually, the whole outermost layer of basalt, up to $5 \mathrm{~cm}$ thick, is removed due to coalescence of single and complex depressions, leaving only a few walls hardened by mineral precipitation in place (Fig. 8). The rock surface is thus exhumed and refreshed, vulnerable to the formation of a new generation of cavernous weathering forms. This process is further facilitated by strong winds that deflate the weathered material, leaving the bare surfaces of caverns exposed for further deterioration. This is evident in the lack of weathering material in most hollows.

The major locational control of the cavernous forms developed on Holmsberg is the proximity to the coast, a finding that corresponds to most previous weathering studies in marine climatic environments (André \& Hall 2005; French 1996; French \& Guglielmin 2000; McKeever et al. 1990). The majority of caverns on the cliff are located on structural discontinuities of bedrock favoring differential weathering and development of cavernous forms (Hacker 2003). In such locations, cracks and fissures within bedrock allow for the intensive penetration of weathering processes. Gas bubbles created during lava cooling form vesicles and spherical marco-pores which are frequently observed in the Holmsberg basalts. These pores can be the foci of enhanced weathering and probably constitute embryonic stages of alveoli development. Evidence of this

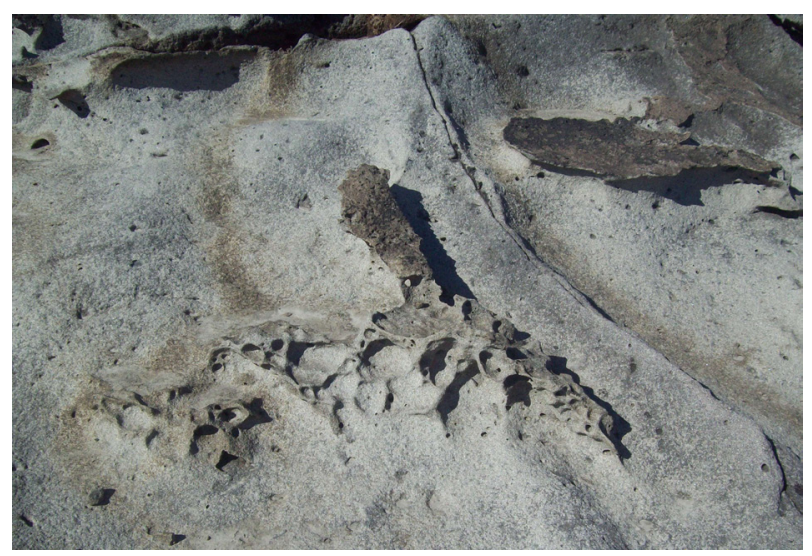

Fig 8. Rock surface partially refreshed by significant removal of weathered surface (phot. K. Zwalińska) is manifest in the observation of weathering rinds around pore walls. The cavernous forms on Holmsberg are developed on northeast or southeast facing rock surfaces which do not receive a lot of sunshine. This is quite extraordinary according to Doe $(2004,2011)$ who emphasizes the role of insolation.

\section{Chemical weathering}

Several subaerial weathering reactions operate within the basalt in the presence of seawater and are evident in the secondary mineral development and presence of weathering rinds on the sampled rock surfaces. The low silica content in the weathering rinds can be attributed to hydrolysis of silicates and aluminosilicates under the influence of seawater that is rich in carbon dioxide. Rusty coatings observed on opaque minerals are due to oxidation of iron- and aluminium-rich minerals including olivine $\left((\mathrm{Mg}, \mathrm{Fe})_{2} \mathrm{SiO}_{4}\right)$. The red, brown and yellow colours found within the weathering rinds (Fig. 9) result from varying degrees of hydration and oxidation of iron minerals (Yoshida 2011).

Chemical decomposition of olivines plays a very important

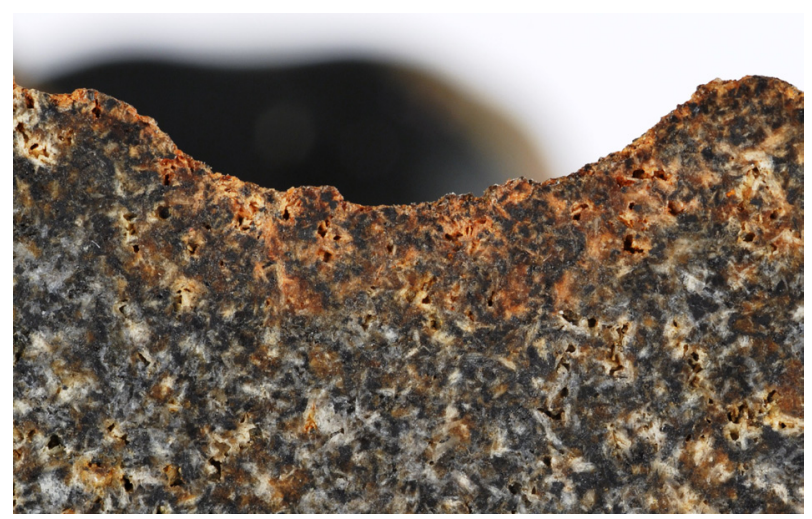

Fig 9. Weathering rind and micro-pores observed in a thin section of basalt (phot. M. Dąbski)

role in formation of tafoni evidenced by the numerous micropores observed in the weathering rinds (Fig. 9) that develop in former locations of olivine. Once such micro-pores form, they are the foci of further chemical and mechanical weathering by enabling more water and air to penetrate the rock.

Chemical weathering of pyroxene (augite) leads to the formation of chlorite, producing a characteristic brown colour. Chloritization can occur under certain conditions, one of which is the introduction of magnesium and iron together with silica and aluminium (Bolewski \& Parachoniak 1988). This process results in iron precipitation within the basaltic weathering rinds and a hardening of the outermost rock surface. It is the presence of this hardened outer layer that is a necessary factor in the creation of the sharp, frequently overhanging, often "C" shaped, tafoni walls. Further weathering is therefore limited to surfaces without the hardened iron precipitate cover (Doe 2011). 


\section{Role of salt}

Proximity to the coast is the key factor in the weathering controls on Holmsberg cliff. Seawater is delivered to the upper parts of the cliff and plays a major role in formation of cavernous weathering forms. Enrichment of feldspars and pyroxenes occurs in the weathering rind with chlorine, manganese and sodium, yet the absence of these same elements in intact rock beyond the weathering rind is clear evidence of their introduction from a salt water source. Unlike in sandstones (Doe 2004, 2011), intact, igneous basalt has low permeability, thus limiting or eliminating the process of drawing salts through capillary action from inside the rock to the rock surface, as proposed by Doe $(2004,2011)$. In our study area, the direct salt water source is sea aerosol. Upon drying of rock, salt crystallises inside the pores leading to mechanical disintegration of basalts and enlargement of caverns. During winter, frost weathering and salt weathering cooperate on the basis of mutual enforcement (summarized by French 1996; French, HM \& Guglielmin, M 2000).

\section{Conclusion}

The cold maritime climate and marine environment of the western Icelandic coast is conducive to the development of cavernous weathering forms in basaltic cliffs. Several factors are important in their observed geographic and site-specific location, dimensions, and weathering compounds. The dominant position of the cavernous forms is at the highest vertical and horizontal surfaces on northeastand southeast facing rock walls. These locations are strongly affected by winds and intensive sea aerosol delivery. Further likelihood of the presence of tafoni is in basalt with a high olivine content, gas bubbles and fractures.

From the mineralogical evidence through comparisons of intact and weathered rock we propose a sequence of stages in the development of tafoni in this area. Chemical decomposition of feldspars, pyroxenes and olivines, on the basis of oxidation and hydrolysis, is responsible for the development of micro-pores and change in colour within the weathering rinds. Enhanced porosity favours further weathering by allowing contact with more air, water and marine salt which, in turn, is responsible for salt weathering. As the rock surface gradually deteriorates, spherical macro-pores (gas bubbles) emerge on the rock surface to create embryonic alveoli which can finally evolve into complex caverns and tafoni. Precipitation of iron on rock surfaces, leading to their hardening, is responsible for the characteristic "C" shape of tafoni walls. Rock decays faster beneath the hardened surface thus allowing growth of tafoni in a mainly sideways direction. Presumably, there is more moisture inside such elementary niches than in the open centres of tafoni which are susceptible to quicker drying, therefore deterioration of rock operates more effectively in the side niches.

Cavernous weathering forms (alveoli, honeycomb, tafoni) can develop in a variety of climates. However, there are some universal environmental factors conducive to their development. The key factors controlled by climate are rock temperature, provision of moisture in the rock and high wind velocity. Salt delivered to the weathering rock surface from inside the rock or directly from sea aerosol plays a very important role. A variety of rock types, including sandstones, granites and basalts, can host cavernous weathering forms, given discontinuities in rock structure, texture, lithology or presence of minerals prone to chemical weathering.

\section{Acknowledgement}

We would like to thank Iwona Gałeczka M.Sc. (from the Institute of Earth Sciences, University of Iceland) for her extensive help and support, as well as Marek Wróbel M.Sc., Justyna Wideńska M. Sc., Grzegorz Kaproń M.Sc., and Piotr Dzierżanowski Ph.D. (from the Faculty of Geology, University of Warsaw) for their time, guidance and input throughout the process of this research. Critical comments of two anonymous referees are kindly acknowledged.

\section{References}

André, MF \& Hall, K 2005, 'Honeycomb development on Alexander Island, glacial history of George VI Sound and palaeoclimatic implications (Two Step Cliffs/Mars Oasis, W Antarctica)', Geomorphology, vol. 65, pp. 117-138.

Benito, G \& Sancho, C 1990, 'Factors controlling tafoni weatering in the Ebro Basin (NE Spain)', Zeitscrift für Geomorphologie, vol. 34, pp. 165-177.

Bolewski, A \& Parachoniak, W 1988, Petrografia, Wyd. Geologiczne, Warszawa. (In Polish)

Doe, NA 2004, 'What makes holes in sandstone', Shale, vol. 9, pp. 12-40.

Doe, NA 2011, 'The geometry of honeycomb weathering of sandstone', Shale, vol. 26, pp. 31-60.

Dragovich, D 1969, 'The origin of cavernous surfaces (tafoni) in granitic rocks of southern South Australia', Zeitschrift fur Geomorphologie NF, vol. 13, pp. 163-181.

Einarsson, MÁ 1984, 'Climate of Iceland' in World Survey of Climatology:
15: Climates of the Oceans, ed $\mathrm{H}$ van Loon, Elsevier, Amsterdam, pp. 673-697.

Einarsson, P 1999, Geology of Iceland. Rocks and Landscape, Mál og menning, Reykjavik.

French, HM 1996, The Periglacial Environment, Longman, Harlow.

French, HM \& Guglielmin, M 2000, 'Cryogenic Weathering of Granite, Northern Victotia Land, Antarctica', Permafrost and Periglacial Processes, vol. 11, pp. 305-314.

Goudie, AS 2004a, 'Honeycomb weathering' in Encyclopedia of Geomorphology ed AS Goudie, Routledge, London-New York, pp. 530.

Goudie, AS 2004b, 'Weathering pit' in Encyclopedia of Geomorphology ed. AS Goudie, Routledge, London-New York, pp. 1115-1116.

Goudie, AS 2004c, 'Tafoni' in Encyclopedia of Geomorphology ed AS Goudie, Routledge, London-New York, pp. 1034-1035.

Hacker, A 2003, Controls of tafoni development in castle rocks, Idaho, Carleton College Press, Northfield. 
Hall, K \& André, MF 2006, 'Temperature observations in Antarctic tafoni: implications for weathering, biological colonization, and tafoni formation', Antarctic Science, vol. 18, no. 3, pp. 377-384.

Hejl, E 2005, 'A pictorial study of Tafoni development from the 2nd millennium BC', Geomorphology, vol. 64, pp. 87-95.

Jennings, JN 1968, 'Tafoni' in Encyclopedia of Geomorphology, ed RW Fairbridge, Reinhold, New York, pp. 1103-1104.

Majerowicz, A \& Wierzchołowski, B 1990, Petrologia skał magmowych, Wyd. Geologiczne, Warszawa. (In Polish)

Martini, IP 1978, 'Tafoni watering, with examples of Tuscany Italy', Zeitschrift für Geomorphologie, vol. 22, no. 1, pp. 44-67.

McKeever, R, Whalley, WB \& Smith, BJ 1990, 'Basalt weathering in a temperate maritime environment', Developments in Soil Science, vol. 19 (C), pp. 519-523.

Szumska, U 1998, Klimat Islandii, M.Sc. theses, University of Warsaw. (In Polish)

Turkington, A 2004, 'Cavernous weathering' in Encyclopedia of Geomorphology, ed AS Goudie, Routledge, London-New York, pp. 128-130.

Williams, RBG \& Robinson, DA 1991, 'Frost weathering of rocks in the presence of salts - a review', Permafrost and Periglacial Processes, vol. 2, pp. 347-353.

Yoshida, H, Metcalfe, R, Nishimoto, S, Yamamoto, H \& Katsuta, N 2011, 'Weathering rind formation in buried terrace cobbles during periods of up to 300ka', Applied Geochemistry, vol. 26, pp. 1706-1721.

Young, RW \& Young, ARM 1992, Sandstone Landforms, Springer-Verlag, Berlin. 